\title{
The Improvement Research of Hoisting Machinery Accidents' Emergency Response Mechanism under the Idea of Safety and Delicacy Management
}

\author{
Peng Xu, Caiwu Lu, Na Lu \\ School of Management, Xi'an University of Architecture and Technology, Xi'an 710055, China \\ xpaiz@126.com
}

Keywords: Construction Site, Hoisting Machinery, Emergency Solutions and Response Mechanism, Safety Management, Delicacy Management

\begin{abstract}
At present the accidents of hoisting machinery happen frequently on construction sites, ensuing serious and endangered consequence. The life and economic lose can be effectively reduced through the emergency solutions and rapid response mechanism in the hoisting machinery accidents. This text focus on the improvement research of emergency solutions and rapid response mechanism by analyzing some problems which exist in process of construction, basing on the idea of safety and delicacy management.
\end{abstract}

\section{Introduction}

The emergency solutions and rapid response mechanism play an important role as a safety management measure on construction sites. It tells us directly the capacity and standard which the enterprises have had in their safety management. More and more hoisting machinery accidents happened in our country recently and what courses this is the extensive management measure. Such a management measure takes unclear staff responsibility, unstandardized guidance and so on, ensuing that the safety management cannot be put in place. The reason why we put in the idea of the safety and delicacy management is to detailed every work, quantify every indicator and makes every job responsible in safety management. So what this text tells about is what this idea means and how to incorporate the idea into the emergency solutions and rapid mechanism.

\section{The Safety and Delicacy Management}

Actually the safety management aims to control and manage the security loophole while its research object is the security risk but not the accidents. Sometimes no accident happens in a construction process but this dose not mean that the safety management is in place because of some security risks may exist in the construction process nothing but the risks are not appeared as a form of the accident. One of the peculiarity of the risk is unpredictability and the aim of the safety management is to recognize, find, eliminate or control the risk. The safety and delicacy management is to penetrate the idea of delicacy management into the system of safety management making the target of the safety management more fast, precise and economized by setting the standard, clarifying the responsibility, allocating the resource, strengthening the education and implementing strictly.

\section{The Problems in the Emergency Solutions and Rapid Mechanism}

The Mechanism can not form the Entire Security Management System as a Whole. Safety and delicacy management is fine for accurate and quick to achieve the goal of security, so the emergency rescue solution based on delicacy management can not be just a piece of paper, not be simply a program or a method approach under the concept of a series of instruments after the accident. Emergency solutions and rapid mechanism should address on the prevention, control and reduction of accidents etc. and should be carried out in every process accounting before, in and after 
the accident, should not be considered as a series of method to solve the problem we face just after the accident. Emergency response plan should be developed into a system by a strict standard, a clear division of responsibilities, implement this system into daily safety management.

Emergency Solutions and Rapid Mechanism cannot be put in Place. On the construction sites, the first one discovering hoisting machinery safety risks, experiencing the accidents are always the workers, but not a leader or a security officer of the project. Currently hoisting machinery emergency solutions are always worked out by mostly members of the units of information or security officer, and who become familiar with the solutions are mostly the leadership and management of the construction, so the solutions cannot be able to implement for each job among staff. Once such security risks appear or accidents happen, workers need to report but not to deal with the situation properly in accordance with the solutions in the first time, thus delaying the timing and coursing incalculable consequences. Safety and delicacy management requires quick and accurate management, so it should be formed as an emergency rescue system as mentioned above and be implemented in the most basic work crowd.

Lacking of Risk Identification Method on Content. Now most of the construction enterprises often have a misunderstanding when they are in the preparation of making hoisting machinery emergency solutions and response mechanism. Most of them consider the significance of the mechanism is reflected after the accident, so ignore the content of the identification of security risks without the accidents happening. To emergency solutions and rapid response mechanism, people will always pay more attention to the latter, and the more content of the mechanism is unfolded in rescuing accident. The so-called emergency, not just anxiousness after the accident, is more cases that should be urgency when hoisting machinery safety risks arise and how to deal with such a situation occurring. This is the lack of the content in the emergency solutions in terms of the urgency and it is also a realization of the content in safety and delicacy management of risk identification, risk analysis and risk exclusion.

Information can not be updated in time. In recent, the preparation of the hoisting machinery emergency solutions and rapid response mechanism in construction enterprises usually is take in only before the installation or using process, but almost no longer modified after then. As a result, emergency solutions become a form of documents, many of which information can not be updated in the long construction process, and its usefulness will be gradually reduced. Depending on the requirements of safety and delicacy management, the mechanism should require a combination of specific conditions of the construction site and need a timely changing of information, especially the relief supplies, means of communication, rescue routes and so on.

\section{The Improvements under the Idea of Safety and Delicacy Management}

The Formation of the Emergency Rescue Management System. Construction enterprises need to implement the emergency solutions and rapid response mechanism into daily safety management of hoisting machinery to form emergency rescue management system and take the emergency measures and the rescue methods into the daily work. The purpose is to be able to detect and control the appearance of safety risks before the accident, be able to organize the rescue and prevent the accident scale expansion without fear when an accident occurs and can investigate the scene methodically after the accident and learn the lessons.

Practice and Implementation. The construction enterprises need take the necessary hoisting technical tests to the on-site operators and the staff need to understand the equipment they use in order that they can be the first one to discover the risks and report it to the manager in the event of a threaten. It needs to strengthen the operational staff education, enhance safety awareness of workers to ensure that they produce habits of ground machinery inspection in their daily work.

Solutions Content must be altered According to the Site. In the construction site, with the duration of the passage of time, the on-site material storage sites, the number of hoisting machinery, transport corridors and other information are constantly changing. Early establishment of emergency mechanism certainly can not take into account all of these aspects. Executives must be sure to modify the content of at different times against the specific environment and must be sure to 
inform all the managers and staff about the content modify, while they must be sure to check the relief material reserves regularly, check the patency of the accident evacuation route and check the various rescue units' communication situation.

Adding the Contents of the Risk Identification. Content of hazard identification should be put in the emergency part of the mechanism while different lifting equipment should be written separately and eventually including the identification and assessment of hazards and other content. Increasing content of risk identification can enhance the expertise of the managers in the hoisting machinery inspections, on the other hand can help field personnel in the event of an accident find the root cause of quickly and take the situation under control.

Using the Techniques of Science. Officers should make full use of modern scientific methods in preparing the emergency mechanism, rather than rely on experience blindly. For example, the preparation of the mechanism in the content related to risk identification and assessment can be solved by using the fault tree method or AHP; facing the content in the distribution of the site relief supplies, you can take advantage of the knowledge-site materials management; when planning the escape routes you can use intelligent algorithms such as the ant colony algorithm to solve. Using the scientific method can make standards set more rigorous, more credible and more persuasive.

The Development of Appropriate Incentives. Safety and delicacy management emphasizes the importance of the aspect of human resources in its content about controlling risks. The reasonable rewards and punishments can be more effective to motivate staff which is very necessary. Personnel who detect safety problems in time or propose optimized ideas should be commended and rewarded, while who hidden the discovery of risks or are not in accordance with the provisions of the mechanism should be criticized or punished.

\section{Conclusion}

Hoisting Machinery emergency solutions and rapid response mechanism developed under the idea of the safety and delicacy management is to prepare the construction enterprise a thought revolution, but also a leap in mechanical emergency rescue plan. The new emergency response plan emphasizes safety risks analysis and investigation, paying attention to the implementation of emergency measures, enhancing the timeliness of rescue operations, enhancing the safety awareness of staff, establishing the overall emergency rescue system as the core, in order that the safety emergency rescue to the hoisting machinery on construction site can be more accurate and rapid.

\section{Acknowledgements}

Foundation: Shaanxi key disciplines of special funds to finance projects (E08001)

\section{References}

[1] M. Zhou. Optimization of safety production supervision mode of coalmining enterprises. Journal of China University of Mining and Technology,15(4), December, 2005, 348-353

[2] Leonard Green. Implementation of lean manufacturing in a small sized company. UMI: Pro Quest information and learning company, $2004: 83-90$

[3] Glenn Maples. Anna Greeo. Ron heady. John Tanner .Teaching Project Management and Cost Engineering. AACE International Transaction. Morgantown: 2005:156-160

[4] N. Xu. The discovery of delicacy management in school security work. Manager' journal. 2014(4):231-254

[5] Q.P. Lou. The delicacy management of cranes' staggered operation in a large construction site. Building Construction. 2009, 31(10):923-924

[6] K.S. Wu. The problems and countermeasure to the hoisting machinery management. The world of building material. 2009, 30(6):74-77 